\title{
Departamento de Psicologia da PUC-Rio: 60 ANOS DE FORMAÇÃO E PRODUÇÃO DE CONHECIMENTO ${ }^{I}$
}

Terezinha Féres-Carneiro*

\section{Resumo}

Este texto narra um pouco da história dos 60 anos do Departamento de Psicologia da PUC-Rio, ressaltando seu pioneirismo nas atividades de formação e de produção do conhecimento. Em 1953, Hanns Lippmann criou, no Instituto de Psicologia Aplicada (IPA), o primeiro Curso de Formação de Psicólogos do país, que começou a ser ministrado nas enfermarias da Santa Casa de Misericórdia e, em 1957, foi transferido para o campus recém-inaugurado da Gávea. Em 1966, o Departamento implantou o primeiro Curso de Mestrado em Psicologia do país. O Curso de Doutorado foi iniciado em 1985. Com grande tradição na área da Psicologia Clínica e com incontestável liderança no cenário nacional, o Departamento de Psicologia da PUC-Rio, até o ano de 2013, já titulou 4.584 psicólogos, 722 mestres e 166 doutores.

Palavras-chave: psicologia; graduação; mestrado; doutorado; história.

\begin{abstract}
DEPARTMENT OF PSYCHOLOGY AT PUC-RIO: 6O YEARS OF TRAINING AND KNOWLEDGE PRODUCTION

This text narrates a piece of the 60 years' story of the Psychology Department at PUC-Rio, emphasizing its pioneer character in training and in producing knowledge. In 1953 Hanns Lippmann created the Institute for Applied Psychology (IPA), the first Training Course for Psychologists in the country, which classes were then in the Santa Casa wards. In 1957 the course was transferred to the newly opened campus in Gávea. In 1966 the Department implemented
\end{abstract}

* Pontifícia Universidade Católica do Rio de Janeiro, Rio de Janeiro, RJ, Brasil. 
the first Masters Course in Psychology in Brazil. The PhD Course started in 1985. With great tradition in the field of Clinical Psychology and with undisputed leadership in the national scenario, the Psychology Department had titled, until 2013, 4.584 psychologists, 722 masters, and 166 doctors.

Keywords: psychology; undergraduate; masters; PhD; history.

\section{Resumen}

DEPARTAMENTO DE PSICOLOGÍA DE LA PUC-RIO: 6O AÑOS DE FORMACIÓN Y PRODUCCIÓN DE CONOCIMIENTO

En este trabajo se narra parte de la historia de los 60 años del Departamento de Psicología de PUC-Rio, destacando sus actividades pioneras en la formación y producción de conocimiento. En 1953, Hanns Lippmann creó el Instituto de Psicología Aplicada (IPA), el primer Curso de Formación de psicólogos en el país, que comenzó a ser enseñada en las salas de la Santa Casa de la Misericordia, y en 1957 fue trasladado a lo nuevo campus de la Gávea. En 1966, el Departamento implementó el primer curso de Maestría en Psicología del país. El curso de Doctorado se inició en 1985. Con gran tradición en el ámbito de la Psicología Clínica y de liderazgo indiscutible en el panorama nacional, el Departamento de Psicología de la PUC-Rio, hasta el año 2013, tituló 4.584 psicólogos, 722 maestros y 166 doctores.

Palabras clave: psicología; licenciatura; maestría; doctorado; historia.

Proferir a conferência de encerramento do evento comemorativo dos 60 anos do Departamento de Psicologia da PUC-Rio é, para mim, uma grande honra e uma enorme alegria. Narrar um pouco dessa longa história de formação e de construção do conhecimento me remete também ao meu próprio percurso de docente-pesquisadora. Destes 60 anos de história do Departamento, 46 foram vivenciados por mim com muito entusiasmo e grande alegria.

A história do Departamento de Psicologia da PUC-Rio tem início em 1953, com a criação do Instituto de Psicologia Aplicada (IPA), embora a Psicologia, como disciplina, já fosse ministrada na PUC-Rio desde 1941, no Curso de Filosofia, e de 1943, no Curso de Serviço Social. No IPA, Hanns Lippmann criou o primeiro curso de formação de psicólogos do país. Nilton Campos, catedrático de Psicologia e, posteriormente, diretor do Instituto de Psicologia da Universidade do Brasil, foi um importante colaborador na implantaçâo do curso que começou a ser ministrado no período noturno nas enfermarias da Santa Casa de Misericórdia. O curso tinha a duraçáo de três anos e meio, e o corpo docente era formado por médicos, filósofos e educadores. 
Dos 36 alunos da primeira turma, apenas sete concluíram o curso em dezembro de 1956, dentre eles Aroldo Rodrigues que, posteriormente, teve um importante papel na sua história. O professor Aroldo Rodrigues proferiu a Conferência de Abertura do nosso evento comemorativo dos 60 anos e recebeu, ao final da mesma, uma Homenagem Especial pela relevante colaboração dada ao Departamento nos primórdios da sua história.

Em 1957, o curso foi transferido para o campus, recém-inaugurado, da Gávea e passou a ser ministrado no período diurno, sob a direção do Pe. Antonius Benkö, jesuíta, húngaro, que chegou ao Brasil em 1954. Na Sessão de Abertura desse evento comemorativo dos 60 anos do nosso Departamento, exibimos um vídeo gravado, com o Pe. Benkö, especialmente para essa ocasião. Foi muito emocionante acompanhar a mensagem de boas-vindas e de sucesso para o nosso evento, emitida por ele, hoje com 93 anos. Nessa mensagem, o Pe. Benkö ressaltou o quanto devemos, para além do nosso sucesso pessoal como psicólogos, estar atentos às necessidades emocionais e espirituais do outro.

Pe. Benkö, que dirigiu nosso Departamento por dez anos, juntou-se a membros de outras instituiçóes, unindo esforços em busca da regulamentação da profissão de psicólogo e elaborando propostas ao Legislativo. Em agosto de 1962, a lei 4.119 institucionalizou a formação e a profissão de psicólogo no país. Nos anos seguintes, Pe. Benkö foi chamado para integrar a Comissão de Registro dos Psicólogos, evidenciando, assim, a importância e a representatividade do IPA à época. Essa relevância e esse pioneirismo que o nosso Departamento teve nos primórdios da sua construção se manteve ao longo de toda a sua história.

A Pós-graduação na PUC-Rio está comemorando, neste ano de 2013, seus 50 anos. O primeiro Curso de Mestrado foi implantado na PUC, em 1963, pela Engenharia Elétrica. Três anos depois, em 1966, sob a direção do professor Aroldo Rodrigues, a Psicologia implantou o primeiro Mestrado da área no país. A primeira Dissertação de Mestrado, intitulada "Homeostase psíquica e agradabilidade”, foi defendida no dia 20 de dezembro de 1968, por Leonel Correa Pinto, sob a orientação do professor Carlos Paes de Barros.

Em 1967 (quando eu cursava na PUC-Rio o Colégio Universitário), houve mudanças significativas na estrutura da universidade, dando origem à departamentização das suas unidades. Assim, foi criado o Departamento de Psicologia, juntamente com os demais departamentos. A partir desse momento, o IPA passou a destinar-se apenas às atividades de estágio.

Em 1968 (quando ingressei como aluna no Departamento de Psicologia), o regime de crédito, já implantado anteriormente no CTC (Centro Técnico Científico), foi implantado no CTCH (Centro de Teologia e Ciências Humanas). Nos 
anos que se seguiram, foram criados no Departamento, sob a direção do professor Carlos Paes de Barros, vários setores com diferentes enfoques teóricos, numa tentativa de incentivar o desenvolvimento de abordagens diferentes da Psicanálise, que predominava à época.

Em 1972, quando apenas seis Cursos de Mestrado estavam sendo oferecidos no Brasil na área da Psicologia, nosso curso foi a o primeiro a ser credenciado pelo Conselho Federal de Educação. Todavia o Curso de Doutorado só foi implantado em 1985. Poderíamos nos perguntar por que o primeiro Programa a implantar o Mestrado no país demorou quase vinte anos para implantar o Doutorado. Para compreendermos melhor o adiamento da implantação do nível de Doutorado no nosso Programa de Pós-graduação, retomarei um pouco da história de altos e baixos na sua experiência de formação e de construção do conhecimento.

É importante lembrar, contudo, que em 1976, sob a direção do professor Aroldo Rodrigues, o Departamento de Psicologia implantou um Doutorado conjunto com o Departamento de Educação. A primeira turma desse Doutorado era composta por cinco alunos da Psicologia e cinco alunos da Educação. Participamos dessa primeira turma, como alunos da Psicologia, Bernard Rangé, Cilio Ziviani, Maria Euchares, Vera Lemgruber e eu. Os outros cinco alunos eram do Departamento de Educação. Posteriormente, esse curso desvinculouse do Departamento de Psicologia, permanecendo apenas como um Doutorado em Educaçáo e, dos cinco alunos da Psicologia da primeira turma, apenas Maria Euchares Motta nele se doutorou.

No início de julho de 1977, em meio a uma crise instalada no Departamento de Psicologia, o então reitor, Pe. João Augusto MacDowell, me fez um convite para assumir a Direção. Num primeiro momento hesitei e pedi alguns dias para pensar. Como eu, uma jovem que tinha apenas concluído o Mestrado, iria dirigir um Departamento com vários professores-doutores, meus grandes e admirados mestres: Aroldo Rodrigues, Angela Biaggio, Carlos Paes de Barros, Charles Esbérard, Maria Helena Novaes, Monique Augras, dentre outros? Alguns dias depois, apesar da apreensão, aceitei o desafio, agradecendo ao Pe. Mac- Dowell pela confiança.

Dirigi o Departamento de Psicologia de 1977 a 1981 e discuti muito com professores, supervisores e alunos uma proposta para promover várias mudanças na sua estrutura. Entendia que a supervisão era uma atividade docente, todavia os supervisores de estágio eram contratados como técnicos, não como professores. Propus, entáo, que os técnicos psicólogos passassem a ser contratados como docentes e a ministrar disciplinas em suas respectivas áreas de especialização. In- 
centivei que eles cursassem o Mestrado, e propus que o IPA passasse a ser denominado SPA - Serviço de Psicologia Aplicada.

Até 1978, o Curso de Mestrado era oferecido em duas áreas de concentração: Psicologia Teórico-Experimental e Psicologia Clínica. Embora, em muitos momentos, ele tenha sido considerado centro de excelência, em 1978, com a saída de vários professores do Programa, o processo de recredenciamento, feito pelo MEC, considerou o corpo docente limitado em número para duas áreas de concentração e o parecer foi desfavorável.

Como as áreas de especialização dos docentes eram diversas e não havia uma concentração em nenhuma delas, nesse momento, o Programa, para atender à exigência do MEC através da Comissão de Recredenciamento da CAPES, optou por um Mestrado em uma única área, que foi então denominada de Processos Motivacionais. A escolha dessa área, excessivamente ampla, refletiu a constituição do corpo docente da época.

Tendo em vista que, já na sua origem, essa área apresentava problemas, decidimos proceder a uma reavaliação da mesma. Considerávamos que a delimitação de uma única área de concentração deveria refletir uma real articulação e não apenas se constituir numa solução artificial para atender uma exigência do recredenciamento. Tornava-se necessária então uma delimitação de objetivos mais específicos e uma concentração na contratação de recursos humanos para a consecução de tais objetivos.

Em 1982, quando o professor Bernard Rangé dirigia o Departamento de Psicologia e eu era Coordenadora de Pós-graduação, a área de concentração em Psicologia Clínica voltou a ser implantada, com três linhas de pesquisa, tendo em vista a grande tradição do Departamento e a enorme demanda na mesma. Tal reformulação levou o Programa a recuperar sua excelência e a ser avaliado, em 1984, com conceito A pela CAPES.

Nessa ocasiáo, ainda como Coordenadora, eu tinha a ideia fixa de implantar o Doutorado para tirarmos o atraso dos anos anteriores. Fui a Brasília, inúmeras vezes, discutir com Rosana Arcoverde, então responsável pela área de avaliação na CAPES, o Projeto de implantação do Doutorado, que foi aprovado nesse mesmo ano e iniciado em março de 1985.

Em agosto de 1986, quando a professora Maria Elizabeth Ribeiro encontrava-se na Direção do Departamento e a professora Maria Helena Novaes na Coordenação da Pós-graduação, foi lançado o primeiro número da nossa revista Psicologia Clínica, hoje bem avaliada no Qualis CAPES.

Nos oito anos que se seguiram, o Programa de Psicologia Clínica da PUC-Rio manteve o conceito A na CAPES, todavia nas avaliaçóes de 92/93 e 94/95 
o conceito caiu novamente para $\mathrm{B}$, tendo em vista que os prazos para a conclusão dos Cursos, sobretudo do Doutorado, voltaram a ficar muito longos, tendo havido também uma queda na produção bibliográfica do corpo docente.

Nesse mesmo período, sob a direção da professora Maria Euchares Motta, houve uma mudança significativa no currículo da graduação, buscando adequar o curso às novas demandas da realidade social. Nos anos de 1997 e 1998, foi construído o anexo ao prédio Cardeal Leme, ampliando consideravelmente o espaço físico do Departamento. Somos, todos, muito gratos à professora Maria Euchares, cuja ousada iniciativa nos propiciou um ambiente de trabalho confortável e um convívio agradável na nossa copa, onde, entre uma aula e outra, podemos almoçar em meio ao papo descontraído com os colegas.

No início do ano de 1996, recebi da então Diretora, Maria Euchares, e dos colegas do Programa insistentes solicitaçóes para que assumisse, mais uma vez, o cargo de Coordenadora de Pós-Graduação. Havia nessas solicitaçóes dos colegas a esperança de que pudéssemos recuperar a tradição de excelência, perdida nas duas avaliaçôes anteriores.

Aceitei o desafio, passando a discutir com os professores a grande importância da produção docente e da produção discente no processo de recuperação da excelência do Programa. Discutimos mais uma vez uma proposta de reformulação dos Cursos de Mestrado e Doutorado, visando, sobretudo, à redução dos prazos de defesa das dissertações e teses e à articulação das disciplinas às quatro linhas de pesquisa propostas. Reduzimos o número de disciplinas obrigatórias, que ficaram sendo apenas as disciplinas metodológicas e instrumentais para o desenvolvimento das dissertaçóes e teses, e articulamos melhor as eletivas aos temas das pesquisas desenvolvidas pelos professores e alunos. Tais medidas tornaram a produção do Programa mais consistente e articulada.

$\mathrm{O}$ regulamento interno da universidade, à época, estabelecia o prazo de três anos para a conclusão do Mestrado, com dois possíveis pedidos de prorrogação, ou seja, o mestrando poderia fazer o Curso em quatro anos. O prazo para a conclusão do Doutorado, até essa data, era de seis anos, com duas possíveis prorrogaçóes; assim, o doutorando podia fazer o Curso em sete anos. Era preciso ser, na PUC-Rio, "mais realista que o rei" para reduzir tais prazos.

Uma das principais críticas que o nosso Programa havia recebido, na ocasião, era a de que nossos prazos de conclusão do Mestrado e do Doutorado eram extremamente longos. Argumentamos várias vezes com a Coordenação Central de Pós-graduação e Pesquisa da PUC-Rio que era preciso mudar os prazos da Universidade em relação às defesas de dissertaçóes e teses. Tentamos mostrar que prazos tão dilatados era um desserviço que a Universidade prestava aos Progra- 
mas, na medida em que a política de Pós-graduação do país estabelecia prazos muito mais curtos para as defesas. $\mathrm{O}$ fato é que, em menos de dois anos depois destas insistentes conversas, a PUC-Rio reduziu de três para dois anos o prazo de defesa das dissertaçóes e de seis para quatro anos o das teses, havendo sempre a possibilidade de duas prorrogaçóes de seis meses cada.

Com o trabalho conjunto de professores e alunos, reduzimos os prazos de defesa de dissertaçóes e de teses e aumentamos a produçáo qualificada docente e discente, recuperando assim a avaliação 5 na CAPES no biênio 96/97.

Entretanto, no triênio seguinte (98/99/2000), o Programa aumentou o prazo médio de defesas, sobretudo das teses de Doutorado (tendo em vista que o novo regulamento da Universidade passou a ter vigência apenas para os alunos que entraram a partir de 1999). Além disso, o programa teve a produção docente reduzida; tendo sido ressaltado pela CAPES que uma das linhas de pesquisa apresentava produção bibliográfica muito baixa.

De 1998 a 2000, o Departamento foi dirigido pela professora Claudia Garcia, que organizou em 2000 a comemoração dos 40 anos do SPA, que teve seu campo de ação ampliado, com a abertura de novas áreas de estágio e com a criação das Jornadas Clínicas Anuais do SPA, que permanecem até hoje.

Nos seis anos que se seguiram (de 2000-2006), o Departamento, dirigido pela professora Ana Maria Rudge, ampliou o número de equipes de diferentes abordagens no SPA, além de ter promovido a reforma do seu espaço físico e a informatização dos seus arquivos.

Em 2001, a professora Ana Maria Rudge e os colegas da Pós-graduação insistiram para que eu aceitasse, mais uma vez, a Coordenação de Pós-graduação com o objetivo de recuperar o papel de liderança que, por tantos anos, o Programa de Psicologia Clínica da PUC-Rio exerceu no cenário nacional da Pós-graduação. Pela terceira vez, aceitei o desafio.

Nesse momento, o Departamento de Psicologia teve mais uma posiçáo inovadora na Universidade. Discutimos, nas reunióes do corpo docente, a necessidade de implantar no Programa o procedimento de credenciamento para orientação na Pós-graduação não apenas para o ingresso de professores no Programa, mas também para a permanência deles no mesmo. Tal procedimento foi aprovado pelo conjunto dos professores, que elegeram uma Comissão de Credenciamento composta por quatro docentes (dois professores associados e dois professores titulares).

Como resultado desse trabalho os professores que, no final de 2001, não apresentaram a produção bibliográfica considerada necessária pela referida Comissão não foram credenciados para orientar na Pós-graduação, não tendo re- 
cebido, assim, alunos novos. Tal procedimento, uma criação pioneira do nosso Programa, passou a vigorar, posteriormente, no regulamento dos Programas de Pós-graduação da PUC-Rio. Fazer isso, certamente, foi uma experiência difícil e dolorosa, pois implicou na saída de alguns colegas da Pós-graduação, mas essa era a única alternativa para recuperarmos a avaliação do Programa.

Mais uma vez, os esforços envidados pelo corpo docente e pelo corpo discente da Pós-graduação no sentido, sobretudo, de incrementar a produção bibliográfica e de reduzir os prazos de defesa das dissertaçóes e teses foram coroados com o resultado da avaliação da CAPES referente ao triênio 2001/2002/2003, na qual nosso Programa recuperou a avaliação 5.

No segundo semestre de 2004, um novo arranjo das linhas de pesquisa foi discutido e proposto, visando à entrada no Programa de Pós-graduação de professores com produçáo bibliográfica de qualidade que se encontravam atuando apenas em nível de Graduação.

De 2006 a 2010, a professora Maria Elizabeth Ribeiro dirigiu o Departamento pela segunda vez, implantando os Estágios Básicos no Curso de Graduação e dando início ao processo de renovação do corpo docente.

Desde 2010, a Direção do Departamento está sendo exercida pelo professor J. Landeira-Fernandez, que promoveu uma nova e cuidadosa reforma no espaço físico e deu continuidade ao processo de renovaçáo do corpo docente, tendo em vista a saída de alguns professores.

O Curso de Graduação, graças ao trabalho conjunto de professores e alunos, recuperou, em 2013, a nota quatro no ENAD. O programa de Pós-graduação, organizado atualmente em quatro linhas de pesquisa: Psicanálise: clínica e cultura; Interação social, linguagem e subjetividade; Família, casal e criança: teoria e clínica; e Clínica e neurociências, tem havido um grande incentivo à produção científica e à internacionalizaçáo, buscando melhorar sua avaliação, passou da nota 5 para a nota 6 na CAPES.

Nos seus 60 anos de existência, o Curso de Graduação em Psicologia da PUC-Rio titulou, com dedicação e cuidado, 4.584 psicólogos, muitos dos quais se encontram hoje exercendo a profissão, com reconhecido destaque no cenário nacional em órgãos públicos e privados. Nos seus 47 anos de atuação, o Programa de Pós-graduação do Departamento de Psicologia da PUC-Rio titulou 722 mestres e 166 doutores, muitos dos quais estáo desempenhando com competência a função de docentes-pesquisadores em inúmeras instituições de ensino superior do país.

Como vimos, foram necessários muitos procedimentos pioneiros, além de muitas reformulaçóes e muitas experiências inovadoras, para que o Departamen- 
to de Psicologia da PUC-Rio, com seu Curso de Graduaçáo e seu Programa de Pós-graduação, pudesse cumprir, nestas seis décadas, a tarefa de produzir conhecimento e de formar psicólogos, mestres e doutores de forma competente e cuidadosa para continuar exercendo o papel de liderança que sempre lhe coube no cenário da Psicologia no Brasil.

Sinto-me feliz e orgulhosa de ter participado tão intensamente e por tanto tempo dessa história, que estamos continuando a construir. São 46 anos, desde que entrei no Departamento de Psicologia como aluna, e 41 anos, desde que ingressei no seu corpo docente. Foi com a alegria daqueles que exercem prazerosa e apaixonadamente o seu ofício que exerci todos os cargos da sua estrutura acadêmico-administrativa: fui Coordenadora de Graduação, Coordenadora Geral de Estágios do SPA, Coordenadora de Pós-graduação e Pesquisa (por três mandatos), Diretora (por dois mandatos), totalizando 22 anos de trabalho acadêmico-administrativo. E é como muita emoçáo que, em nome de todos nós, professores, alunos e funcionários, quero prestar ao Departamento de Psicologia da PUC-Rio uma homenagem, parabenizando todos aqueles que colaboraram na construção da história dos seus 60 anos de formação e de produção do conhecimento.

Para finalizar, gostaria de prestar uma homenagem especial aos nossos mestres, alguns dos quais já falecidos, que foram pioneiros na implantação do Curso de Graduação e do Curso de Mestrado em Psicologia no Brasil e que compartilharam conosco, em várias ocasióes, suas inquietações e seus projetos para a Psicologia brasileira. Eles, que foram pioneiros e inovadores, nos deixaram uma preciosa herança e nos ensinaram que a herança pode ser transformada. Também nós devemos deixar esse legado aos nossos alunos, enquanto desempenhamos nossa função de formá-los para o exercício profissional, para ensino e para a pesquisa.

\section{Nota}

${ }^{1}$ Conferência de Encerramento proferida no evento comemorativo dos 60 anos do Departamento de Psicologia da PUC-Rio: Fórum em Saúde e Responsabilidade Social. 